Full length article

\title{
On the way to learning style models integration: a Learner's Characteristics Ontology
}

\author{
A. Ezzat Labib*, José H. Canós, M. Carmen Penadés \\ ISSI_DSIC, Universitat Politècnica de València, Spain
}

\section{A R T I C L E I N F O}

\section{Article history:}

Received 8 November 2016

Received in revised form

21 March 2017

Accepted 26 March 2017

Available online 27 March 2017

\section{Keywords:}

Learning style models

Ontology

E-learning

Adaptive learning

Personalized learning

Learning characteristics

\begin{abstract}
A B S T R A C T
On the way to increasing customization in e-learning systems, the learner model is the main source of variability. Such a model includes a number of psychological characteristics and study preferences that describe the learner's personality traits related to learning. During the last decades, the design methods and tools for e-learning have been designed assuming specific learner models. Therefore, in the search for a learning environment suitable for as many learner models as possible, we need tools to explore -and exploit- such models. In general, the learner's characteristics can be linked to the so-called learner's learning style (which is a part of the learner model) to provide the instructor with extensive knowledge about the learner's characterization in perceiving and processing information. Numerous learning styles have been proposed in the last decades, in some cases with overlapping characteristics with the same or different names. Thus, the heterogeneity of the learning style space makes it difficult to handle customization effectively. In this paper, we introduce a Learner's Characteristics Ontology based on creating interconnections between the different learning style model dimensions and learning styles with the relevant learner's characteristics, that: (1) helps instructors to improve and personalize the learning content; (2) can recommend learning materials to learners according to their learning characteristics and preferences; (3) can provide both instructors and learners with extensive knowledge about how they can improve their teaching and learning abilities; and (4) can improve communications and interaction between humans and computers by specifying the semantics of the learning style models' characteristics.
\end{abstract}

๑) 2017 Elsevier Ltd. All rights reserved.

\section{Introduction}

The adoption of the Web as "the" platform for the deployment of e-learning environments has paved the way for the long soughtafter customization in learning content management. Due its unique properties, the learner model is considered a pivotal issue to enforce customization/personalization in e-learning environments. It contains an important information about learner's personal data, cognitive traits, knowledge level, and learning styles and preferences, which can be used to adapt the e-learning environments to learners' needs. Specifically, the possibility of creating learnerbased content, which varies in terms of the learners' different characteristics, is still being pursued by learning environment designers. These characteristics have been formalized through the concept of learning style, which is part of the learner model and,

\footnotetext{
* Corresponding author.

E-mail address: alabib@dsic.upv.es (A.E. Labib).
}

surprisingly, is not easy to define. Several studies on learning styles defined them as the individuals' approaches to learning based on their own preferences (Felder \& Silverman, 1988; Honey \& Mumford, 2000; Kolb \& Kolb, 2005; Ramayah, Sivanandan, Nasrijal, Letchumanan, Leong, 2009). For us, a learning style will represent a set of characteristics, mostly related to personality and attitude, that a person shows when participating as a student in a learning process. In most cases, the characteristics are grouped into dimensions that are in turn grouped into what is called a Learning Style Model.

Since the early works in the 1970s, when the term "learning style model" was coined, the learning community has produced successive refinements that have resulted in a large list of proposals, many of them having some degree of overlapping concepts. As a matter of fact, in (Coffield, Moseley, Hall, \& Ecclestone, 2004) 53 different learning style models were classified into a hierarchal structure called Families of Learning Styles, and 13 learning style models were evaluated regarding the theory behind each model. 
Such diversity makes the development of a general purpose, multimodel learning tool very difficult. As a consequence, researchers often tend to adopt one learning style model, leaving others uncovered. Kurilovas and Juskeviciene created a Web 2.0 tool ontology to interconnect learning activities with appropriate Web 2.0 tools. The learning activities were extracted from the VARK (Visual-Verbal-Read/write-Kinesthetic) learning style (Kurilovas \& Juskeviciene, 2015). On the same line, Ouf and colleagues proposed a framework for e-learning ecosystems; they categorize learning activities according to the Felder-Silverman model only (Ouf, Abd Ellatif, Salama, \& Helmy, 2016).

Several research works concluded that paying attention to learner's learning characteristics increase the effectiveness and efficiency of teaching and learning activities (Kurilovas \& Juskeviciene, 2015; Santos \& Boticario, 2015; Thalmann, 2014; Truong, 2016). Ocepek and colleagues combine different learning style models with preferred types of multimedia learning materials for the purpose of designing a learning system (Ocepek, Bosnić, NančovskaŠerbec, \& Rugelj, 2013). Santos and Boticario developed a set of practical guidelines to produce personalized recommendations for online courses (Santos \& Boticario, 2015). Fouad proposed an approach for Semantic and personalized search of learning contents based on learning style and learning objects metadata (Fouad, 2011). Yasir and Sharif (2011) introduced a new adaptation approach of matching learning contents with learning styles and their influence on learner's achievement.

The variation in learner's learning characteristics, which is a substantial part of the learner model, is an important concern for addressing several issues e-learning systems must address, such as supporting personalized/adaptive learning material design and development, defining criteria to be used by recommender systems to suggest materials according to some learning characteristics, assisting learners to semantically search for learning materials, and enabling knowledge reusability for both humans and systems. We want to develop a generic learning materials authoring tool. By generic we mean that, unlike existing tools -linked to one or more learning style models- our tool will be able to search and reuse learning content regardless of the learning style model it was created with. Such feature requires what we could call semantic learning style models interoperability, provided by a catalog of learning styles, their characteristics, and the relationships between them.

In this paper, we introduce the Learner's Characteristics Ontology, which provides the conceptual base of the semantic interoperability between learning style models. The ontology was built from the analysis of six learning style models that we considered relevant according to the criteria explained later in the paper. We describe the models in detail, and compare them to find overlapping concepts from which to construct inter-model mappings. We also describe the steps taken in the development of the ontology, and give clues about the role it will have in LOAT, the Learning Objects Authoring Tool currently under development.

The rest of the paper is organized as follows. In Section 2, we give an overview of the main concepts behind our work. Section 3 contains the description of the six learning style models chosen for our study, making emphasis in their similarities. Section 4 describes the development process of the Learner's Characteristics Ontology using On-To-Knowledge methodology. Section 4 introduces a discussion about the approach. Finally, our conclusions and remarks on future work conclude the paper.

\section{Preliminaries}

Customization/personalization models in the e-learning domain are built on top of a few concepts that we describe in this section.
The goal is to create learning materials adapted to particular student characteristics, trying to optimize his/her abilities and then learn better and faster.

\subsection{Learner model}

A learner model, sometimes called student model (Riad, ElMinir, \& El-Ghareeb, 2009) is the system's representation of a specific learner's characteristics that may be relevant for personalized interaction. The learner model is not intended to be a representation of the mental state of the learner; rather, it contains several learner's details such as personal information, cognitive traits, knowledge level, and learning styles and preferences (Murray \& Pérez, 2015). Furthermore, in personalized e-learning systems, learner models catch and save data about learners' personal information, knowledge, preferences, needs, learning goal, and learning styles. These data are grouped in two sets, namely domain-specific information and domain-independent information. The first set includes information about the learner's knowledge (e.g. knowledge level, insight about knowledge, etc.), and the second one is in turn divided into two information subsets: the psychological model and the generic model of the learner. The former contains data related to learner emotional and behavioral aspects, whereas the latter includes information about learner interests, learning goals, motivations, experience, and preferences (Brusilovsky, 1994; Murray \& Pérez, 2015).

There are several learner model standards published in the elearning field. The IEEE ${ }^{1}$ Public and Private Information standard, called PAPI Learner (IEEE, 2001) and the IMS $^{2}$ Learner Information Packaging standard (IMS, 2002) are among the most used nowadays.

\subsection{Learning style \& learning style model}

The learner's learning style describes the learner preferred way in which he/she perceives, processes and retains information during a learning process. One of the most important elements of a learner model, the learning style is a component of the domainindependent information, and describes "characteristic cognitive, effective, and psychosocial behaviors that serve as relatively stable indicators of how learners perceive, interact with, and respond to the learning environment" (Curry, 1981). Kolb and Kolb gave their own view of learning style as "the description of individual differences in learning based on the learner's preference for employing different phases of the learning cycle" (Kolb \& Kolb, 2006).

A learning style defines learner behavior in terms of a set of characteristics such as Diverging (the divergent learners are emotionally-oriented, and tends to be creatively) or Converging (the convergent learners have interest in application and applies logic and concept).

In general, learners show more than one learning style, corresponding to different characteristics that can be observed on them. Moreover, researchers found different patterns corresponding to the aggregation of specific learning styles in individuals. Those patterns were called learning style models. They are compositions of several aspects that describe the modes in which learners perceive and process information. Different learning style models employed different theories on defining and categorizing learning styles, as we show in Section 3.

\footnotetext{
${ }^{1}$ Institute of Electrical and Electronics Engineers - www.ieee.org.

2 Instructional Management System project - www.imsglobal.org.
} 


\subsection{A conceptual framework for learning style models}

To summarize the above definitions, as well as to make their interrelationships explicit, we have defined a metamodel that represents the domain of learning style models. This metamodel is the conceptual base for the construction of the Learner's Characteristics Ontology that we will use in the integration of the different learning style models. Fig. 1 shows the metamodel defined using the Unified Modeling Language class diagram notation. For us, a learning style model (represented by the Learning_Style_Model class) is composed of a number of dimensions (Dimension class) representing individual ways of dealing with information (e.g. Perception, Ordering, etc.). Subsequently, each dimension is made up as a discrete spectrum or two opposite poles (e.g. a Perception dimension can be defined by two poles: Intuitive and Sensing; similarly, an Ordering dimension can be defined by Sequential and Randome poles).

Each pole (Pole class) is described by several learner's characteristics (Characteristic class). We introduce this class to ease the management of the semantic searches of learning materials because a learner's characteristic represents a preference or feature of a pole. Finally, a learning style (Learning_Style class) is typically built from two or four poles. For instance, an Assimilating learning style is formulated by combining the Abstract Conceptualization and Reflective Observation poles. On the other hand, learning styles are also associated to characteristics to facilitate the semantic searches. The cardinalities of the relationships in the conceptual model come from the study of different learning styles, as we describe below.

\section{A review of learning style models}

In this section, we introduce the six learning style models that were included in our study. There were two criteria behind the selection of these models. Firstly, according to the classification model suggested by Curry in (Curry, 1983) known as the Onion Model. Curry introduced a model to organize types of learning style models based on a survey of 21 identified models. The model was initially structured into three strata, from inner to outer: Cognitive Personality, Information Processing, and Instructional Preferences. The Instructional Preferences stratum describes the preferred way the individual interacts with the learning environment. The Felder-
Silverman model (see 3.2) is an instance of such stratum. The Information Processing stratum focuses on the individual's approach to process information. Two models representing this stratum are Kolb (see 3.1) and Honey \& Mumford (see 3.6). Finally, Cognitive Personality stratum describes the learning behavior associated with the individual's personality style, not with the learning environment. Riding (see 3.3), Myer-Briggs (see 3.4), and Gregorc (see 3.5) models represent the inner stratum. The second criterion we used to select the learning style models was their extensive usage in scientific papers, as pointed out by (Özyurt \& Özyurt, 2015). We describe the six learning style models selected in terms of the conceptual model shown in Fig. 1.

\subsection{Kolb's Experiential Learning Theory}

Following works of Dewey, Lewin and Piaget, the Experiential Learning Theory was developed by D. Kolb in 1970. Kolb believed that each person has his/her own characteristics or preferences that help him/her to learn better. To Kolb, knowledge came from the blending of Perceiving or Grasping and Transforming Experience (Kolb \& Kolb, 2005). He defined a learning model composed of two orthogonal dimensions, one for Grasping and another for Transforming. The Grasping dimension poles are Concrete Experience (CE) and Abstract Conceptualization (AC). Similarly, the Transforming poles are Reflective Observation (RO) and Active Experimentation $(A E)$. The characteristics associated to each dimension pole are listed in Appendix A1.

Kolb also defined four learning styles obtained from combining the Grasping and Transforming dimensions:

- Diverging (CE-RO). Diverger students favor collecting information extensively and tend to be imaginative thinkers.

- Assimilating ( $A C-R O)$. They have some abilities like collecting information, converting it into a global view and creating theoretical models.

- Converging ( $A C-A E)$. The converger students favor dealing with applications and problems and prefer to come to the decision after solving the problem.

- Accommodating ( $C E-A E)$. Learning through doing and feeling is a good way for accommodators. They are excellent in working with groups.

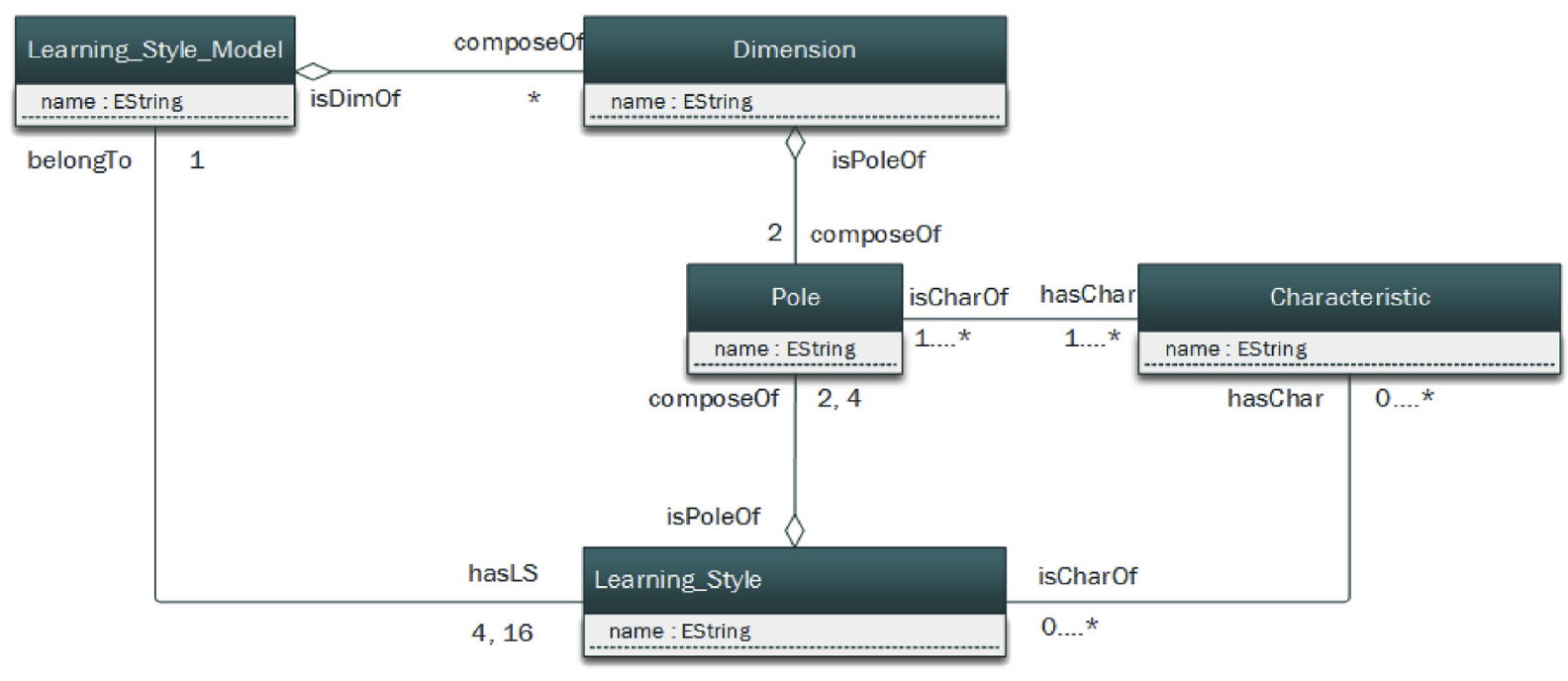

Fig. 1. Metamodel of the learning style models domain. 


\subsection{The Felder-Silverman model}

The Felder-Silverman learning style model is composed of four dimensions (Felder \& Silverman, 1988). The information Perception dimension (Intuitive/Sensing poles) derives from Jung's personality type theory (Jung, 1990). Intuitive persons tend to be creative, oriented toward principles and theories, and able to discover possibilities and relationships. In contrast, Sensory persons are patient with details and concerned with facts, procedures, and concrete contents. The information Processing dimension (Active/Reflective poles) is derived from Kolb's Experiential Learning Theory. Active persons acquire knowledge best by trying things out and working with others in groups. On the other hand, Reflective persons acquire knowledge best through thinking about things, then reflecting on the learning materials, and prefer to work alone or with one trusted person. The Input modality dimension (Visual/Verbal poles) was extracted from the cognitive theory. Visual persons like to receive information through pictures and diagrams, whereas Verbal persons like to retain information through written and spoken demonstrations. Finally, the Understanding dimension (Sequential/ Global poles) was derived from Pask's learning style model. Sequential persons learn in small incremental steps, they are interested in details and prefer convergent thinking and analysis. Global persons understand in intuitive leaps and prefer to use Holistic Thinking. Felder and Silverman combined the four dimensions to define sixteen learning styles (Intuitive-Active-VisualSequential, Intuitive-Active-Visual-Global, etc.) (Felder \& Silverman, 1988). The characteristics associated to each dimension pole are listed in Appendix A1.

\subsection{The Riding cognitive style model}

The Riding cognitive style model was designed as a twodimensional model (Riding, 1991). On one hand, the Wholist/ Analytical dimension is derived from the work of Witkin on field dependence and field independence (Witkin, Moore, Goodenough, \& Cox, 1977) and describes the human way of organizing and processing information. Wholist people can perceive and process information globally, while Analytical people can organize and process information into a number of small parts. On the other hand, the Verbal/Imagery dimension, dependent on the work of Paivio's dual coding theory (Riding, 1991), describes the human mental representation of information. Verbalizer students prefer to represent information in words, whereas the Imagers prefer to represent information in a pictorial way. The characteristics associated to each dimension pole are listed in Appendix A1. Four learning styles are defined: Wholist-Imagery, Wholist-Verbal, Analytical-Imagery and Analytical-Verbal (Riding, 1991; SadlerSmith \& Riding, 1999).

\subsection{The Myer-Briggs Type Indicator theory}

The Myer-Briggs Type Indicator (MBTI) Theory was also developed on the basis of Jung's personality type theory (Jung, 1990). The MBTI theory has four dimensions that refer to the individual's personality types or preferences (Myers, McCaulley, Quenk, \& Hammer, 1998). Each dimension has two uncorrelated poles, and each person tends to one pole in each dimension. So, sixteen unique personality types were generated. The four dimensions represent the core functions our personalities perform throughout our lives. The first dimension (Sensing/Intuitive poles) focused on how individuals perceived and gathered information. People with a Sensing personality function prefer to grasp and receive information literally. On the other hand, people with an Intuitive trait prefer to translate information into possibilities and associations; they prefer to comprehend the global view and ignore the details. The second dimension (Thinking/Feeling poles) describes how individuals come to decisions and make judgments. Thinking people prefer to use analytical logic, while, Feeling people prefer to come to a decision according to the personal impact. The third dimension (Extravert/Introvert poles) explains the individual's attitude to life. The last dimension (Perceiving/Judging poles) determines an individuals' attitude to the outside world. Perceiving people prefer to continue collecting information instead of coming to a decision. In contrast, the dominant trait for Judging people is their decision making (Cohen, 2008). The characteristics associated to each dimension pole are listed in Appendix A1.

\subsection{Gregorc's mind styles model}

Gregorc's model has two dimensions, namely Perception and Ordering (Gregorc, 1982). Firstly, the Perception dimension (Concrete/Abstract poles) describes two ways of grasping information. The Concrete pole explains how individuals prefer to grasp information through their five senses. Concrete persons deal with facts and reality and are interested in practical applications. On the other hand, the Abstract pole explains how individuals can visualize information that cannot be seen. Abstract persons tend to be intuitive and imaginative. Secondly, the Ordering dimension (Sequential/ Random poles) describes the ways in which individuals arrange, order, and reference information. The Sequential pole represents how individuals deal with information in a linear and organized manner. Sequential persons prefer to plan things out step-by-step and are interested in details. The Random pole represents how individuals deal with information in chunks and skipping steps. Random persons are able to make connections between concepts and ideas. The characteristics associated to each dimension pole are listed in Appendix A1. Gregorc combined the two dimensions, leading to four learning styles: Concrete-Random, ConcreteSequential, Abstract-Random, and Abstract-Sequential (Gregorc, 2006).

\subsection{Honey and Mumford's model}

Honey and Mumford defined four learning styles in their model, based on Kolb's learning cycle: The learning styles are Activist, Reflector, Theorist, and Pragmatist (Honey \& Mumford, 1992). Each style has shared characteristics with a particular stage of Kolb's learning cycle. Activists learn best from short here-and-now tasks and they tend to be more eager about new ideas. They prefer to work with others and like to tackle problems by brainstorming. Reflectors prefer to learn by collecting and observing information then thinking about it. They like to generate analyses and reports. Theorists learn best through complex tasks and from theories and facts. They have the ability to visualize things by seeing the broad picture. And finally, Pragmatists learn best through hands-on experiences and practical applications. They enjoy solving problems and decision making (Honey \& Mumford, 2000). The characteristics associated to each learning style are listed in Appendix A2.

\subsection{Observations on learning style models}

From our study on the six learning style models, we conclude that several common characteristics are shared among several dimensions in different models. Table 1 shows the linking between the dimensions of several learning style models described above and the common characteristics identified. Due to space limitations, only 25 of the shared characteristics are shown in Table 1. Here we list only three of the relationships found: 
Table 1

Some Characteristics related to Dimensions of Learning Style Models ${ }^{a}$.

\begin{tabular}{|c|c|c|c|c|c|c|c|c|c|c|c|c|c|c|c|c|c|c|c|c|c|c|c|c|c|c|c|c|}
\hline \multirow[t]{3}{*}{ Characteristics } & \multicolumn{28}{|c|}{ Learning Style Models } \\
\hline & \multicolumn{4}{|c|}{ Kolb's Dimensions } & \multicolumn{8}{|c|}{ Felder-Silverman's Dimensions } & \multicolumn{4}{|c|}{ Riding's Dimensions } & \multicolumn{8}{|c|}{ Myer-Briggs's Dimensions } & \multicolumn{4}{|c|}{ Gregorc's Dimensions } \\
\hline & $\begin{array}{l}\text { Kolb- } \\
\mathrm{CE} \\
\end{array}$ & $\begin{array}{l}\text { Kolb- } \\
\text { AC } \\
\end{array}$ & $\begin{array}{l}\text { Kolb- } \\
\text { RO } \\
\end{array}$ & $\begin{array}{l}\text { Kolb- } \\
\mathrm{AE}\end{array}$ & $\begin{array}{l}\text { FS- } \\
\text { S }\end{array}$ & $\begin{array}{l}\text { FS- } \\
\text { IN } \\
\end{array}$ & $\begin{array}{l}\text { FS- } \\
\mathrm{A}\end{array}$ & $\begin{array}{l}\text { FS- } \\
\mathrm{R} \\
\end{array}$ & $\begin{array}{l}\text { FS- } \\
\mathrm{Vi} \\
\end{array}$ & $\begin{array}{l}\text { FS- } \\
\mathrm{Vr} \\
\end{array}$ & $\begin{array}{l}\text { FS- } \\
\text { Sq } \\
\end{array}$ & $\begin{array}{l}\text { FS- } \\
\text { Gl } \\
\end{array}$ & $\begin{array}{l}\text { Rid- } \\
\mathrm{W} \\
\end{array}$ & $\begin{array}{l}\text { Rid- } \\
\text { A }\end{array}$ & $\begin{array}{l}\text { Rid- } \\
\mathrm{Vr} \\
\end{array}$ & $\begin{array}{l}\text { Rid- } \\
\text { I }\end{array}$ & $\begin{array}{l}\text { MB- } \\
\mathrm{S}\end{array}$ & $\begin{array}{l}\text { MB- } \\
\text { IN } \\
\end{array}$ & $\begin{array}{l}\text { MB- } \\
\text { Th } \\
\end{array}$ & $\begin{array}{l}\text { MB- } \\
\mathrm{Fe} \\
\end{array}$ & $\begin{array}{l}\text { MB- } \\
\text { Ext } \\
\end{array}$ & $\begin{array}{l}\text { MB- } \\
\text { Intr } \\
\end{array}$ & $\begin{array}{l}\text { MB- } \\
\mathrm{Pr} \\
\end{array}$ & $\begin{array}{l}\text { MB- } \\
\text { Jd }\end{array}$ & $\begin{array}{l}\text { Gre- } \\
\text { C }\end{array}$ & $\begin{array}{l}\text { Gre- } \\
\text { A }\end{array}$ & $\begin{array}{l}\text { Gre- } \\
\mathrm{S} \\
\end{array}$ & $\begin{array}{l}\text { Gre- } \\
\mathrm{R}\end{array}$ \\
\hline Literal Manner & $x$ & & & & $x$ & & & & & & & & & & & & $x$ & & & & & & & & $x$ & & & \\
\hline Tangible Facts & $x$ & & & & $x$ & & & & & & & & & & & & $x$ & & & & & & & & $x$ & & & \\
\hline Direct, Hands-on Experience & $x$ & & & & $x$ & & & & & & & & & & & & $x$ & & & & & & & & $x$ & & & \\
\hline Practical & $x$ & & & & $x$ & & & & & & & & & & & & $x$ & & & & & & & & $x$ & & & \\
\hline Concrete Thinking & $x$ & & & & $x$ & & & & & & & & & & & & $x$ & & & & & & & & $x$ & & & \\
\hline Look at The Big Picture & & $x$ & & & & $x$ & & & & & & & & & & & & $x$ & & & & & & & & $x$ & & \\
\hline Imagination & & $x$ & & & & $x$ & & & & & & & & & & & & $x$ & & & & & & & & $x$ & & \\
\hline Analyzing and Interpreting & & $x$ & & & & $x$ & & & & & & & & & & & & $x$ & & & & & & & & $x$ & & \\
\hline Theoretical Connections & & $x$ & & & & $x$ & & & & & & & & & & & & $x$ & & & & & & & & $x$ & & \\
\hline Logical Thinking & & $x$ & & & & $x$ & & & & & & & & & & & & $x$ & & & & & & & & $x$ & & \\
\hline Linear Thinking & & & & & & & & & & & $x$ & & & $x$ & & & & & & & & & & & & & $x$ & \\
\hline Pictorial & & & & & & & & & $x$ & & & & & & & $x$ & & & & & & & & & & & & \\
\hline Written Demonstration & & & & & & & & & & $x$ & & & & & $x$ & & & & & & & & & & & & & \\
\hline Holistic Thinking & & & & & & & & & & & & $x$ & $x$ & & & & & & & & & & & & & & & $x$ \\
\hline Divergent Thinking & & & & & & & & & & & & $x$ & & & & & & & & & & & & & & & & $x$ \\
\hline Content Map & & & & & & & & & & & & $x$ & $x$ & & & & & & & & & & & & & & & $x$ \\
\hline Working with others in Groups & & & & $x$ & & & $x$ & & & & & & & & & & & & & & $x$ & & & & & & & \\
\hline Experimentalists & & & & $x$ & & & $x$ & & & & & & & & & & & & & & & & & & & & & \\
\hline An Active, Doing Approach & & & & $x$ & & & $x$ & & & & & & & & & & & & & & & & & & & & & \\
\hline Engage in Projects & & & & $x$ & & & $x$ & & & & & & & & & & & & & & $x$ & & & & & & & \\
\hline Introspection & & & $x$ & & & & & $x$ & & & & & & & & & & & & & & & & & & & & \\
\hline Theoreticians & & & $x$ & & & & & $x$ & & & & & & & & & & & & & & & & & & & & \\
\hline Observation of Others & & & $x$ & & & & & $x$ & & & & & & & & & & & & & & & & & & & & \\
\hline Use Analytical Logic & & & & & & & & & & & & & & & & & & & $x$ & & & & & & & & & \\
\hline $\begin{array}{l}\text { Decisions based on Personally Held } \\
\text { Values }\end{array}$ & & & & & & & & & & & & & & & & & & & & $x$ & & & & & & & & \\
\hline
\end{tabular}

${ }^{\mathrm{a}}$ Appendix $\mathrm{B}$ describes the acronyms of the column headers of the table. 
- A learner related to Kolb's Concrete Experience (Kolb-CE), Felder-Silverman's Sensing (FS-S), MBTI's Sensing (MB-S), and Gregorc's Concrete (Gre-C) dimensions has several common characteristics like Literal Manner, Tangible Facts, Direct and Hands-on Experience, Practical, and Concrete Thinking, among others.

- The Felder-Silverman's Intuitive (FS-IN), Kolb's Abstract Conceptualization (Kolb-AC), MBTI's Intuitive (MB-IN), and Gregorc's Abstract (Gre-A) dimensions have various common characteristics, like Look at The Big Picture, Imagination, Endless Possibilities, Analyzing and Interpreting, Theoretical Connections, Logical Thinking, etc.

- A learner related to both Felder-Silverman's Global (FS-Gl) and Riding's Wholist (Rdi-W) dimensions has several common characteristics, like Holistic Thinking, Divergent Thinking, and Content Map.

Additionally, several common characteristics are related to several learning styles in different models. For instance, Gregorc's Concrete-Sequential, Honey and Mumford's Theorist, MBTI's ISTJ (Introvert-Sensing-Thinking-Judging), and Felder-Silverman's Sensing-Active-Visual-Global learning styles share a single characteristic named "Tangible Facts." Furthermore, several characteristics are also associated with both dimensions and learning styles at the same time. Also, the Honey and Mumford's Theorist learning style is characterized by the "Theoretical Connection" characteristic in Table 2, and related to MBTI's Intuitive (MB-IN), Kolb's Abstract Conceptualization (Kolb-AC) and Gregorc's Abstract dimensions (Gre-A), see Table 1.

Peter Honey and Alan Mumford developed four learning styles based on Kolb, with no clear dependence on basic dimensions, as do almost all the other learning style models. Honey and Mumford's learning style model and its' characteristics are interconnected. Table 2 gives the characteristics of various learning styles related to Honey and Mumford's learning style model. For example, the Pragmatist student prefers to be Practical and enjoys Problem-Solving. Similar mappings have been made for the other learning style models. In this way we established the interconnections between the learning style models dimensions, learning styles, and related characteristics.

\section{The Learner's characteristics ontology}

Ontologies have become a key enabling technology in several fields and are widely used in domains such as the semantic web, artificial intelligence and, in general, wherever there is a need to structure the concepts of a domain (Mellouli, Bouslama, \& Akande, 2010). As defined by Gruber in 1993, an ontology is "an explicit specification of a conceptualization" (Gruber, 1993). In 1998, Staab \&Studer refined this definition into "an Ontology is a formal, explicit specification of a shared conceptualization" (Staab \& Studer, 2009).

From the perspective of e-learning, where there is no single model for either the learner's personality or content structure, the formal description of knowledge is important for integration and interoperability between models. Moreover, the explicit description of knowledge weakens the assumptions on the implicit nature of information (Rani, Nayak, \& Vyas, 2015). In particular, using ontologies as tools for specifying the semantic interoperability of different learning style model characteristics could improve communication and interaction between computers and humans by specifying the semantics of learning style model characteristics used in the human-computer communication process.

\subsection{Developing Learner's characteristics ontology}

Developing an ontology from a conceptual model that represents a generalization of several models, like the one we introduced in Section 2.3, is a complex task. Sometimes, the knowledge implicitly makes the ontology formalization process difficult. Ontological Engineering provides several methodologies for creating the ontology in a complete and organized way. Several methods for ontology construction have been proposed in the past, as described in (Gómez-Pérez, Fernández-López, Corcho, 2004).

Our goal is to interconnect learning style model dimensions and learning styles with relevant learner's characteristics. In this work, we use the On-to-knowledge ontology development methodology (Sure, Staab, \& Studer, 2009) to build the learner's characteristics ontology. This methodology has a Knowledge Meta Process, which consists of five phases. The feasibility study phase consists of identifying the resources. At the end of this phase, the developer must decide whether it possible to continue the development process or not. The kick-off phase is concerned with the establishment of the ontology requirements specification. It provides a semi-formal description of the ontology (using tables, conceptual maps and text). The refinement phase goal is to create an application-oriented target ontology according to the requirements specification produced before. Finally, the evaluation and maintenance phases serve as a proof for the correctness and usefulness of

Table 2

Characteristics of Honey and Mumford's learning styles.

\begin{tabular}{|c|c|c|c|c|}
\hline \multirow[t]{2}{*}{ Characteristics } & \multicolumn{4}{|c|}{ Honey and Mumford's learning styles } \\
\hline & Activist & Reflector & Theorist & Pragmatist \\
\hline Here-and-Now Tasks & $x$ & & & \\
\hline Brainstorming & $x$ & & & \\
\hline Action Learning & $x$ & & & \\
\hline Working in Small Groups & $x$ & & & \\
\hline Collects data \& Analyses & & $x$ & & \\
\hline Observing and Thinking & & $x$ & & \\
\hline Self-directed Learning & & $x$ & & \\
\hline Cautious and Thoughtful & & $x$ & & \\
\hline Theories \& Facts & & & $x$ & \\
\hline Theoretical Connections & & & $x$ & \\
\hline Drawing information into a systematic and logical Theory & & & $x$ & \\
\hline Complex Tasks & & & $x$ & \\
\hline Trying out new Ideas and Theories & & & & $x$ \\
\hline Practical Applications & & & & $x$ \\
\hline Action Learning & & & & $x$ \\
\hline Problem-Solving & & & & $x$ \\
\hline
\end{tabular}




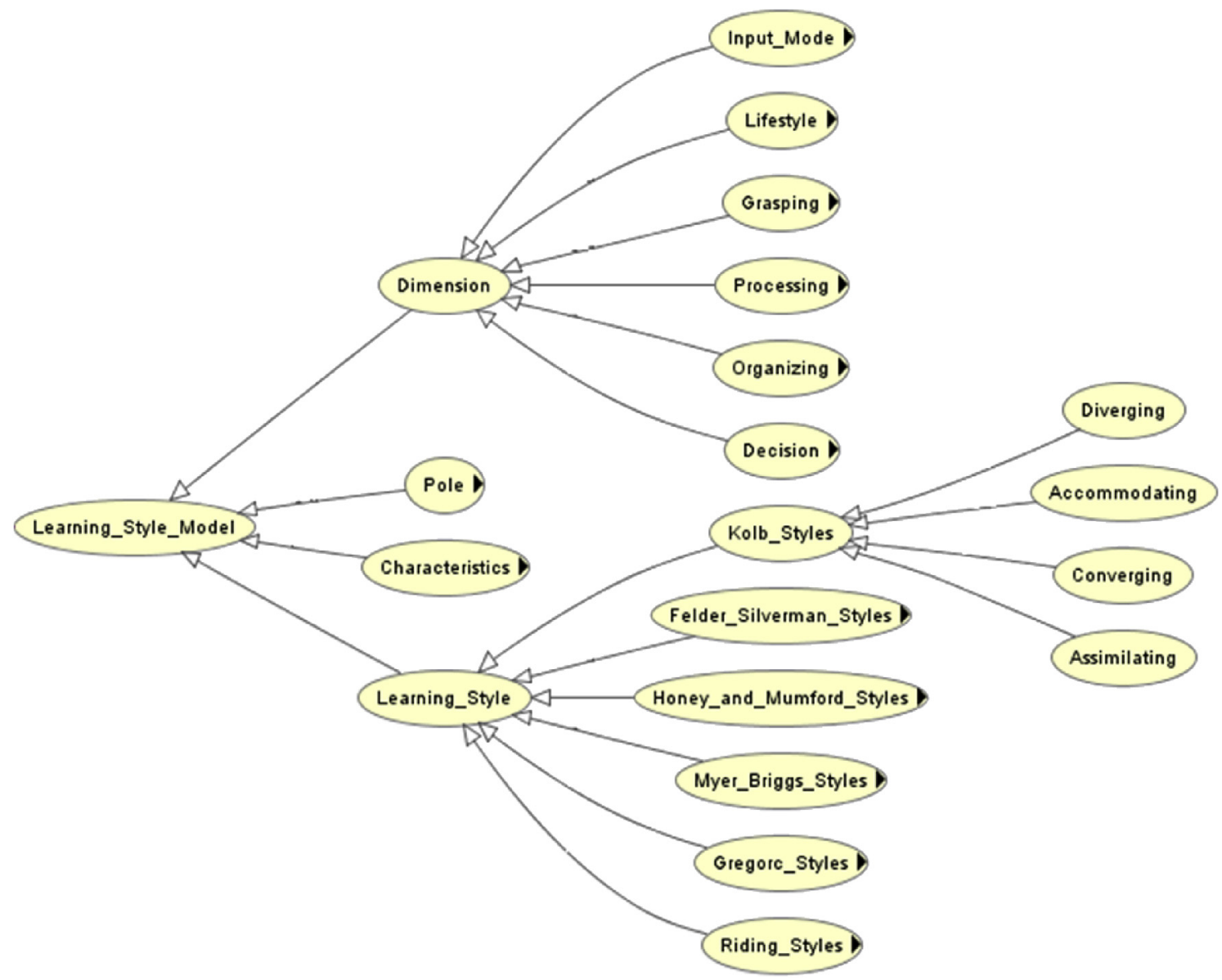

Fig. 2. Partial view of the Learner's Characteristics Ontology.

the ontology. Then the ontology is deployed and can improve over time. In the rest of this section, we describe the steps followed to create the Learner's Characteristics Ontology.

\subsubsection{Feasibility study phase}

In this first phase, we identified several information resources related to learning style models. Many information resources are available on the Internet. To create the ontology, we collected information from studies available in scientific databases (ScienceDirect $^{3}$, IEEE Xplore ${ }^{4}$, CiteSeer ${ }^{\mathrm{x}}$, and Google Scholar ${ }^{6}$ ), Elsevier journals, and Springer journals.

A report by Coffield investigated the existence of 71 learning style models and defined a family of learning styles that contain approximately 53 models, 13 of which were evaluated in (Coffield et al., 2004). We chose the six models described in Section 3 according to two criteria: extensive usage in scientific research, and Curry's classification of learning styles (Cognitive Personality, Information Processing, and Instructional Preferences).

\subsubsection{Kick-off phase}

In this phase, we executed the learning characteristics extraction process, and the information that will be used in the ontology must be presented. A corpus of learner's characteristics selected

\footnotetext{
${ }^{3}$ www.sciencedirect.com.

4 www.ieeexplore.ieee.org.

5 www.citeseerx.ist.psu.edu.

6 www.scholar.google.com.
}

from two perspectives: model dimension and learning style.

For each perspective, a group of characteristics related to one particular learning style model were extracted. The characteristics were then categorized by model dimension and learning style. For instance, the characteristics "Imagination, Look at The Big Picture, Endless Possibilities, Analyzing and Interpreting, Theoretical Connections, Logical Thinking" were grouped into Felder-Silverman's Intuitive (FS-IN) dimension (see Table 1). Similarly, the characteristics "Complex Tasks, Theories \& Facts, Analytical Reviewing, Drawing Information into a Systematic and Logical Theory" were related to the Theorist learning style in Honey and Mumford's model.

These characteristics refer to several concepts with different relationships. The representation of these concepts and relationships and the construction of the learner's characteristics ontology are described in the next phases.

\subsubsection{Refinement phase}

The third phase of the Knowledge Meta process is Refinement, composed of three sub-phases:

- Baseline taxonomy: according to the initial specification obtained in previous phases, the baseline taxonomy is required to formulate application-oriented ontology initially. Fig. 2 shows a partial view of the learner's characteristic ontology.

- Elicitation: several knowledge entities were obtained from the Kick-off phase as follows: 
- The Learning Style Model (Learning_Style_Model) representing the six learning style models.

- The Model Dimension (Dimensions) specifying all dimensions related to each model.

- The Learning Style (Learning-Style) specifying all learning styles related to each model.

- The Pole (Pole) specifying all poles related to each dimension.

- Characteristics (Characteristics) containing all characteristics related to learning styles and dimensions.

- A shared Characteristic may be related to several Dimensions and/or several learning styles at the same time.

- Formalization: according to the specifications and the knowledge entities obtained above, ontological entities (Concepts) were organized in hierarchies. Fig. 3 shows the topmost-level Concepts of the ontology.

At the end of the Refinement phase, the main classes/concepts and relationships/properties were defined in the Learner's Characteristics Ontology. Consequently, the ontology obtained after this phase had to be encoded in a suitable ontology language.

We used the World Wide Web Consortium's Web Ontology Language $^{7}$ (OWL) (Hitzler, Krötzsch, Parsia, Patel-Schneider \& Rudolph, 2012) for ontology encoding, and the Protégé ${ }^{8}$ framework (http://protege.stanford.edu) for developing and maintaining ontologies. In OWL, the user can specify taxonomies for classes and properties. A class is interpreted as a set that contains individuals. The OWL Relationship/Property is a binary relation between two individuals. The property is Characteristic of links the individual Learning_Characteristics to the individual LS_Dimensions_Model and Learning_Style_Models. We have defined the ontology classes (Fig. 3) and relationships between classes.

\subsubsection{Evaluation and maintenance phase}

Once the Learner's Characteristics Ontology had been built using OWL and checked via the standard Protégé reasoner, the Evaluation phase started. We applied several query examples to test the consistency and verify the usefulness of the proposed ontology. We used the DL Query ${ }^{9}$ (a standard Protégé plug-in), which provides an easy-to-use feature for querying and searching in an ontology. Fig. 4 presents two query examples of the learner's characteristics related to the Kolb learning style. The first one shows characteristics related to a learner that has Diverging learning style as a dominant learning preference (see Fig. 4(a)). Several learners have a multi-learning style (bi- or tri-learning style). In the second query example, the learner's characteristics related to the Kolb Converging and Diverging learning styles are displayed (see Fig. 4(b)).

On the way to the development of a learning style modelindependent authoring tool, we aim at bridging the gap between the different learning style models. We also plan a more exhaustive evaluation in the mid-term, when a prototype of the Learning Object Authoring Tool (LOAT) will be available. LOAT is a tool that enforces reuse, customization, and personalization to increase the efficacy of LO authoring processes (Labib, Carmen Penadés, Canós, \& Gómez, 2015). Following the classical component content management system architecture, we are designing and implementing LOAT on top of three basic models: the Instructional Model, the Personalization Model (which contains the Learner's Characteristic Ontology) and the Product Line Model. Additionally, we integrate the Learner's Characteristic Ontology to help authors to create

\footnotetext{
7 www.w3.org/OWL.

8 www.protege.stanford.edu.

9 www.protegewiki.stanford.edu/wiki/DLQueryTab.
}

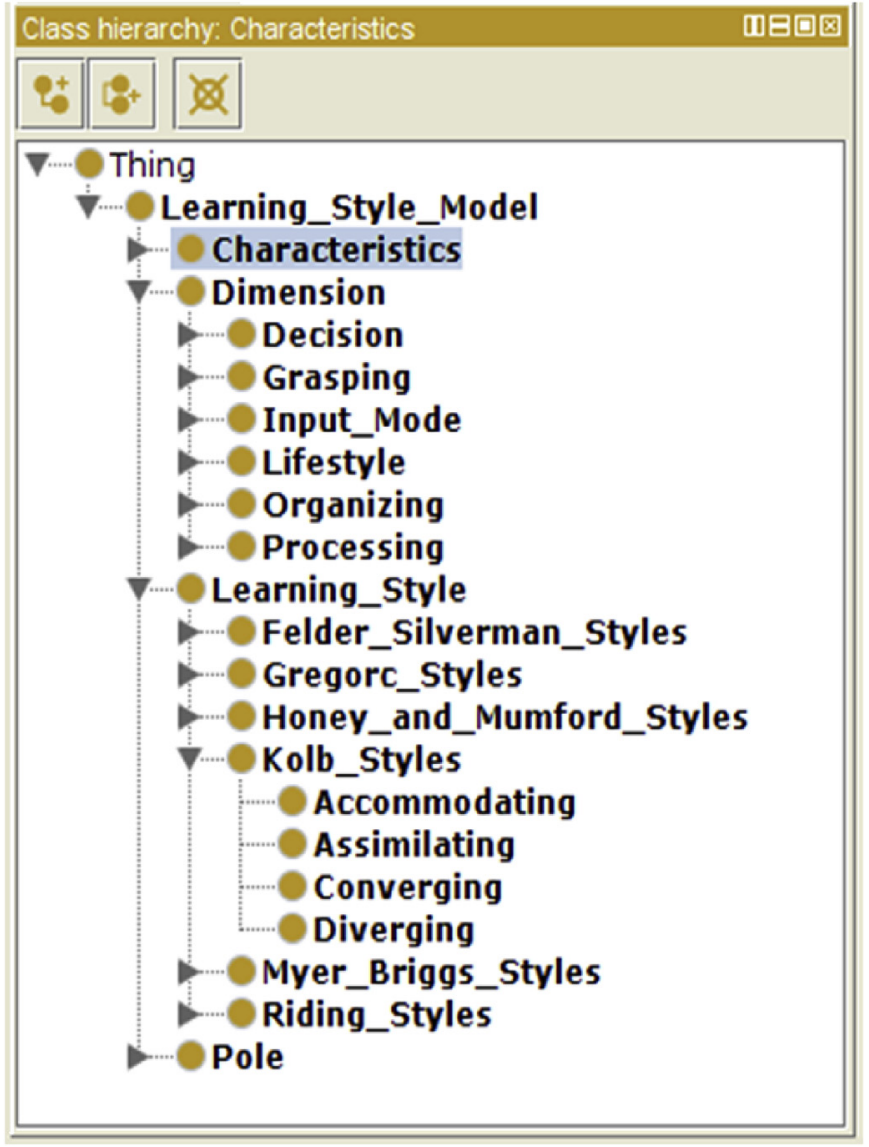

Fig. 3. The upper-level concepts.

learning materials that meet learners' characteristics and preferences. Upon this, we have great flexibility in reusing and producing mass personalized e-learning materials in different delivery formats.

To illustrate how the Learner's Characteristic Ontology can be exploited in LOAT, we use as an example of the initial steps of generating a learning object entitled "If Statement", which is part of an "Introduction to Java Programming" course. Initially, the author needs to fill the learning object metadata form, as shown in Fig. 5.

Later, the Personalization Model provides the author with an authoring guide that offers a catalog of learner's characteristics and learning activities that should be taken into consideration during the authoring process. Additionally, the Personalization Model recommends several components that related to the learning object's learning style or learning characteristics. Fig. 6 shows the learner characteristics and the recommended learning objects. Notice that two learning objects are recommended, one related to Kolb's Diverging and the other to Felder's Sensing-Reflective style which have similar characteristics.

\section{Conclusions}

Among the challenges associated with content personalization in e-learning systems, dealing with the heterogeneity of learning style models is a particularly complex task. With the aim of providing instructors with cross-model facilities, in this paper we have introduced a Learner's Characteristic Ontology which links the learning style model dimensions and learning styles with relevant learner's characteristics. The ontology was built following 


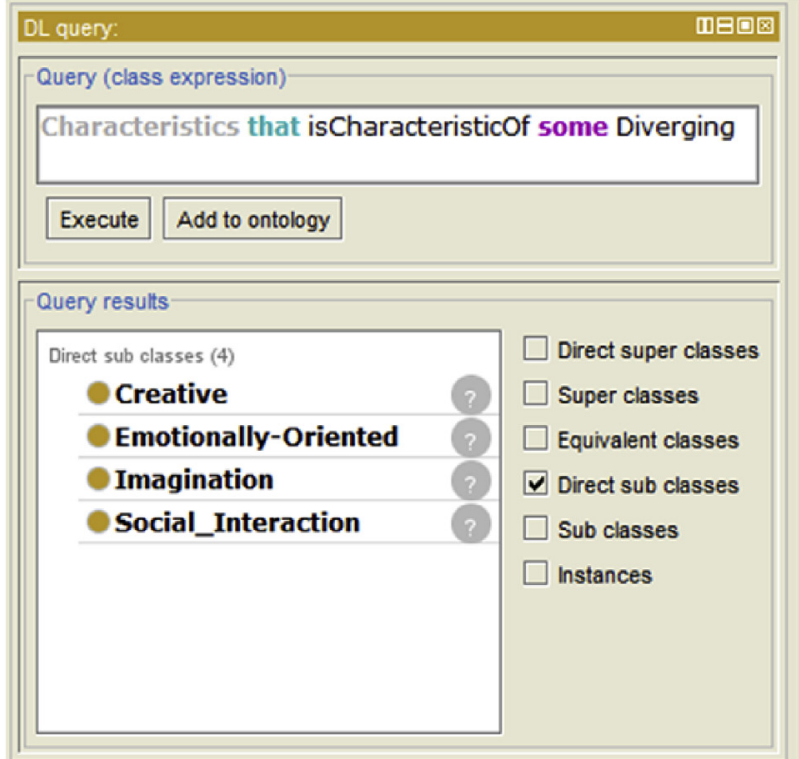

(a)

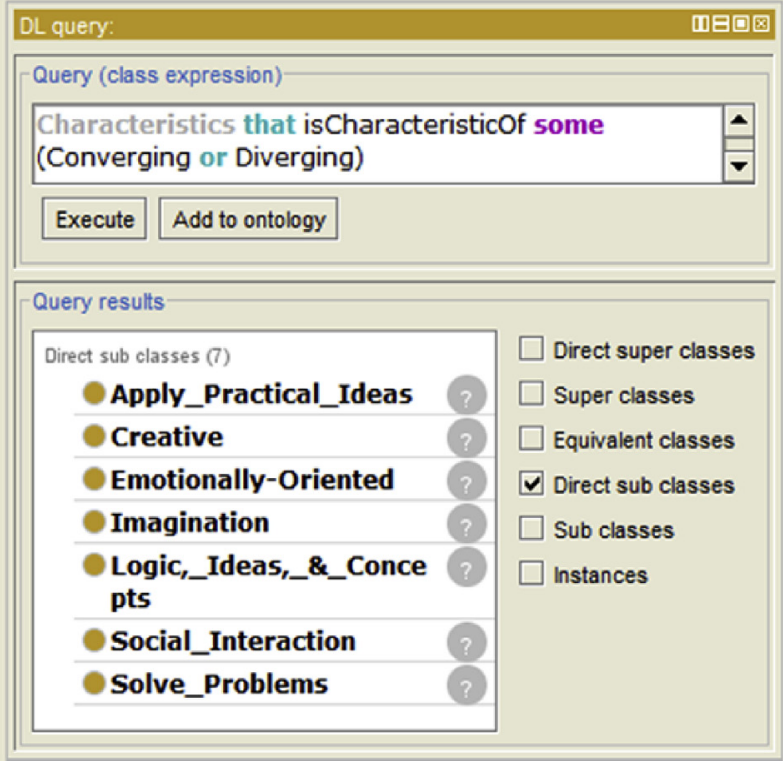

(b)

Fig. 4. Query examples. (a) For finding Learner's Characteristics of Diverging learning style. (b) For bi-learning styles (Converging and Diverging).

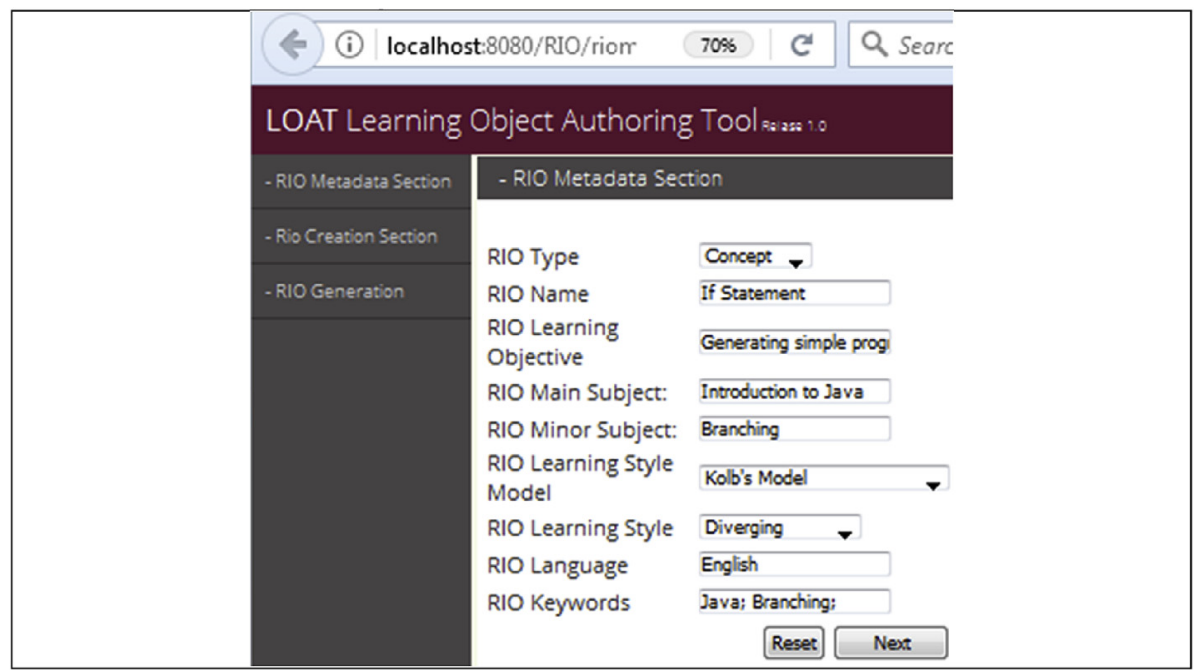

Fig. 5. Metadata form

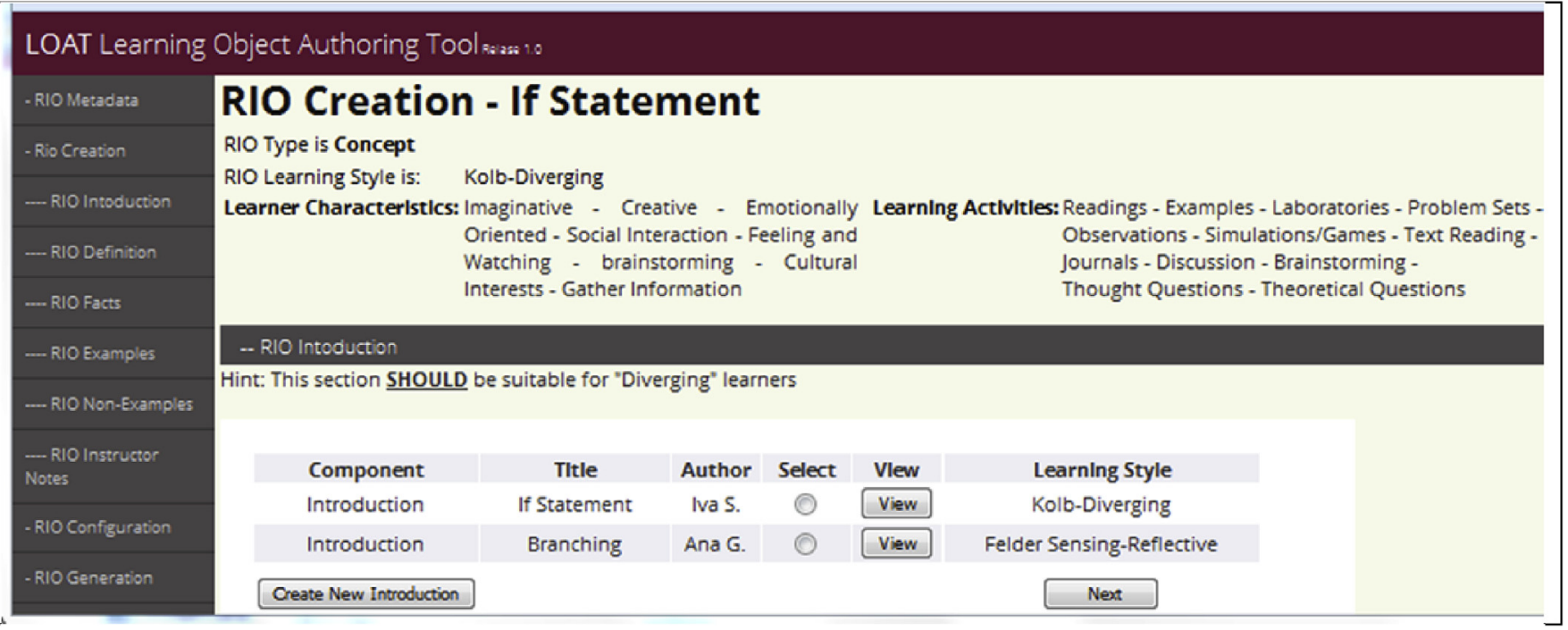

Fig. 6. The Learning Objects and Learner Characteristics recommendations. 
the On-To-Knowledge methodology from the comparative study of six learning style models we selected according to different criteria. We have defined semantic relationships between concepts from different learning style models that will be the key for implementing semantic searches of learning materials developed following different learning style models. The learner's characteristics ontology is important for the instructor to semantically search for suitable contents during the learning content authoring process for the purpose of content reusability. A first prototype of semantically enriched authoring tool is the so-called Learning Object Authoring Tool (LOAT), first described in (Labib et al., 2015). It is aimed at providing real assistance to instructors in the learning materials authoring process with a high degree of content reuse and supporting different learner models.

A full-fledged LOAT is currently under development. Given the high number of learning style models, we plan to keep the ontology growing by incorporating new learning style models. We also plan to develop a content recommender utility as a complement of the semantic search mechanism. As a mid-term goal, we plan to develop an instructional environment complementary to LOAT that allows learners to take advantage of the semantic relationships in their autonomous learning processes.

\section{Acknowledgment}

The work of J. H. Canós and M. C. Penadés is funded by the Spanish MINECO under grant CALPE (TIN2015-68608-R).

\section{Appendix A}

Characteristics

A1. Learning Style Model Dimensions Characteristics

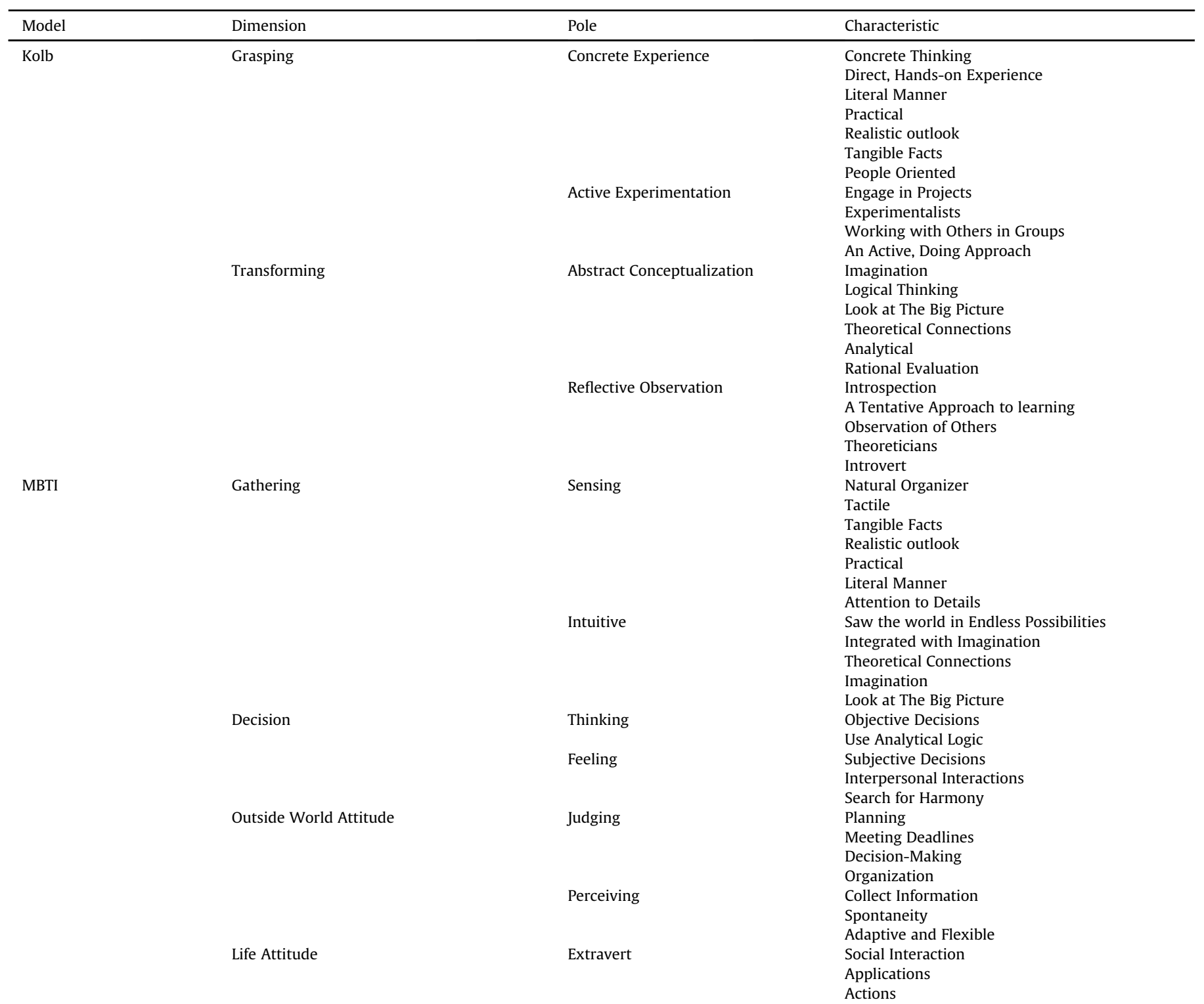


(continued)

\begin{tabular}{|c|c|c|c|}
\hline Model & Dimension & Pole & Characteristic \\
\hline \multirow{32}{*}{ Felder-Silverman } & \multirow{12}{*}{ Perception } & Introvert & $\begin{array}{l}\text { Reflective } \\
\text { Isolated } \\
\text { Working Quietly } \\
\text { Independent Thinkers } \\
\text { Concepts and Idea } \\
\text { Introspection }\end{array}$ \\
\hline & & \multirow[t]{6}{*}{ Sensing } & Memorizing Facts \\
\hline & & & Patient with Details \\
\hline & & & Doing Hands-on Work \\
\hline & & & Practical and Careful \\
\hline & & & Concerned with Procedures \\
\hline & & & Concrete Thinking \\
\hline & & \multirow[t]{5}{*}{ Intuitive } & Discovering Possibilities and Relationships \\
\hline & & & Like Innovation \\
\hline & & & Grasping New Concepts \\
\hline & & & Abstractions and Mathematical Formulations \\
\hline & & & Work Faster \\
\hline & \multirow[t]{7}{*}{ Processing } & \multirow[t]{3}{*}{ Active } & Learning best by Doing \\
\hline & & & Working with Others in Groups \\
\hline & & & Experimentalists \\
\hline & & \multirow[t]{4}{*}{ Reflective } & Introspective processing \\
\hline & & & Independent Work \\
\hline & & & Theoreticians \\
\hline & & & Prefers Thinking through Things \\
\hline & \multirow[t]{9}{*}{ Understanding } & \multirow[t]{4}{*}{ Sequential } & Understanding in Linear Steps \\
\hline & & & Learns in Small Incremental Steps \\
\hline & & & Linear Thinking \\
\hline & & & Orderly \\
\hline & & \multirow[t]{5}{*}{ Global } & Absorbing Material almost Randomly \\
\hline & & & Holistic Thinking \\
\hline & & & Learns in Intuitive Leaps \\
\hline & & & See the Connections no one else sees \\
\hline & & & Systems Thinkers \\
\hline & \multirow[t]{4}{*}{ Input Modality } & \multirow[t]{2}{*}{ Verbal } & Prefers Written and Spoken Explanations \\
\hline & & & Verbal Ability \\
\hline & & \multirow[t]{2}{*}{ Visual } & Prefers Visual Representations \\
\hline & & & Visual Ability \\
\hline \multirow[t]{11}{*}{ Riding } & \multirow[t]{7}{*}{ Organizing and Processing } & Wholist & Global View of Information \\
\hline & & & Information is presented in Holistic \\
\hline & & & Information is presented with a Content Map \\
\hline & & & Tend to be Social \\
\hline & & Analytical & Information is presented in Parts \\
\hline & & & Tend to be Isolated \\
\hline & & & Interested in Details \\
\hline & Information Mental Representation & Verbal & Prefers Textual/Verbal Information \\
\hline & & & Tends to be Extraversion \\
\hline & & Imagery & Prefers Pictorial Information \\
\hline & & & Tends to be Introversion \\
\hline Gregorc & Perception & Concrete & Focus is on "Here and Now" \\
\hline & & & Literal Manner \\
\hline & & & Direct, Hands-on Experience \\
\hline & & & Practical Applications \\
\hline & & & Deal with Facts and Reality \\
\hline & & Abstract & Tends to be Intuitive \\
\hline & & & Tends to be Imaginative \\
\hline & & & Theories and Ideas \\
\hline & & & Analyzing and Interpreting \\
\hline & & & Thinking and Reflecting \\
\hline & Ordering & Sequential & Deals with data in a Linear manner \\
\hline & & & Deals with data in an Organized manner \\
\hline & & & Plan things out Step-By-Step \\
\hline & & & Bottom-up Learner \\
\hline & & & Details \\
\hline & & Random & Information in Chunks, Skipping steps \\
\hline & & & Non-Linear Approach \\
\hline & & & Top-down Learner \\
\hline & & & Makes Connections between Concepts and Ideas \\
\hline
\end{tabular}


A2. Honey \& Mumford Learning Styles Characteristics

\begin{tabular}{ll}
\hline Learning Style & Characteristic \\
\hline Activist & Here-and-Now Tasks \\
& Brainstorming \\
& Action Learning \\
& Working in Small Groups \\
& Experience-driven \\
& Open-minded \\
& Enthusiastic about new situations \\
& Try anything once \\
& Act first and consider the consequences afterwards \\
& Collects data \& Analyses \\
& Observing and Thinking \\
& Self-directed Learning \\
& Cautious and Thoughtful \\
& Observing and listening to others \\
Reflector & Reviewing and pondering on experience \\
& Look at experience from different viewpoints \\
& Comprehensive compilation of information \\
& Theories \& Facts \\
& Analytical Reviewing \\
Drawing information into a systematic and logical Theory \\
Complex Tasks \\
Theoretical Connections \\
Step-by-step upward logic \\
Tend to be perfectionists \\
Systematic thinking \\
Independent \\
Trying out new Ideas and Theories \\
Practical Applications \\
Action Learning \\
Problem-Solving \\
Put Ideas into Practice \\
\\
\end{tabular}

\section{Appendix B}

Acronyms

\begin{tabular}{ll}
\hline Kolb-CE & Kolb - Concrete Experience \\
Kolb-AC & Kolb - Abstract Conceptualization \\
Kolb-RO & Kolb - Reflective Observation \\
Kolb-AE & Kolb - Active Experimentation \\
FS-S & Felder-Silverman - Sensing \\
FS-IN & Felder-Silverman - Intuitive \\
FS-A & Felder-Silverman - Active \\
FS-R & Felder-Silverman - Reflective \\
FS-Vi & Felder-Silverman - Visual \\
FS-Vr & Felder-Silverman - Verbal \\
FS-Sq & Felder-Silverman - Sequential \\
FS-Gl & Felder-Silverman - Global \\
Rid-W & Riding - Wholist \\
Rid-A & Riding - Analytical \\
Rid-Vr & Riding - Verbal \\
Rid-I & Riding - Imagery \\
MB-S & Myer-Briggs Type Indicator - Sensing \\
MB-IN & Myer-Briggs Type Indicator - Intuitive \\
MB-Th & Myer-Briggs Type Indicator - Thinking \\
MB-Fe & Myer-Briggs Type Indicator - Feeling \\
MB-Ext & Myer-Briggs Type Indicator - Extravert \\
MB-Intr & Myer-Briggs Type Indicator - Introvert \\
MB-Pr & Myer-Briggs Type Indicator - Perceiving \\
MB-Jd & Myer-Briggs Type Indicator - Judging \\
Gre-C & Gregorc - Concrete \\
Gre-A & Gregorc - Abstract \\
Gre-S & Gregorc - Sequential \\
Gre-R & Gregorc - Random \\
\hline &
\end{tabular}

\section{Appendix C. Supplementary data}

Supplementary data related to this article can be found at http:// dx.doi.org/10.1016/j.chb.2017.03.054.

\section{References}

Brusilovsky, P. (1994). The construction and application of student models in intelligent tutoring systems. Journal of Computer and System Scences International, 32(10), 70-89.

Coffield, F., Moseley, D., Hall, E., \& Ecclestone, K. (2004). Learning styles and pedagogy in post-16 learning A systematic and critical review. Learning and Skills Research Centre, 84. http://dx.doi.org/10.1016/S0022-5371(81)90483-7.

Cohen, J. J. (2008). Learning style of Myers-Briggs type indicator.

Curry, L. (1981). Learning preferences in continuing medical education. Canadian Medical Association Journal, 124, 535-536.

Curry, L. (1983). An organization of learning styles theory and constructs. Educational Research Information Centre (ERIC). Retrieved from http://files.eric.ed.gov/ fulltext/ED235185.pdf.

Felder, R., \& Silverman, L. (1988). Learning and teaching styles in engineering education. Engineering Education, 78(June), 674-681. http://dx.doi.org/10.1109/ FIE.2008.4720326.

Fouad, K. M. (2011). Using semantic web to support advanced web- based environment. International Journal, 2(12), 120-129.

Gómez-Pérez, A., Fernández-López, M., \& Corcho, O. (2004). Ontological Engineering, 2nd printing. Springer, Verlag.

Gregorc, A. (1982). ORGANON: An adult's guide to style. Columbia, CT: Gregorc Associates Inc.

Gregorc, A. (2006). The mind styles model: Theory, principles and application. AFC.

Gruber, T. R. (1993). A translation approach to portable ontologies. Knowledge Acquisition, 5(2), 199-220.

Hitzler, M., Krötzsch, B., Parsia, P., Patel-Schneider, F., \& Rudolph, S. (2012). OWL 2 web ontology language primer (2nd ed.) W3C recommendation.

Honey, P., \& Mumford, A. (1992). The manual of learning styles (3rd ed.). Maidenhead: Peter Honey. Jensen.

Honey, P., \& Mumford, A. (2000). The learning styles Helper's guide. Maidenhead: Peter Honey Publications Ltd.

IEEE P1484.2.1/D8. (2001). Draft standard for learning technology - public and private information (PAPI) for learners (PAPI learner) - core features. Technical report. Available Online: http://metadata-standards.org/Document-library/Meetingreports/SC32WG2/2002-05-Seoul/WG2-SEL-042_SC36N0175_papi_learner_ core features.pdf.

IMS Learner Information Packaging Information Model Specification. (2002) Version 1.0 final specification. IMS Global Learning Consortium. Available online: http://www.imsglobal.org/profiles/lipinfo01.html.

Jung, C. G.. (1990). Psychological Types. (R.F.C. Hull, Trans. 3rd ed., Vol. 6. Bollingen Series XX). New York.

Kolb, A. Y., \& Kolb, D. A. (2005). The Kolb learning style inventory - version 3. 2005 technical specifi cations. LSI Technical Manual, 1-72. http://dx.doi.org 10.1016/S0260-6917(95)80103-0.

Kolb, A. Y., \& Kolb, D. A. (2006). Learning styles and learning spaces: A review of the multidisciplinary application of experiential learning in higher education. In R. Sims, \& S. Sims (Eds.), Learning styles and learning: A key to meeting the accountability demands in education. Nova Publishers.

Kurilovas, E., \& Juskeviciene, A. (2015). Creation of Web 2.0 tools ontology to improve learning. Computers in Human Behavior, 51, 1380-1386. http:/ dx.doi.org/10.1016/j.chb.2014.10.026.

A. E. Labib, M. Carmen Penadés, J. H. Canós, A. Gómez (2015). Enforcing reuse and customization in the development of learning objects: a product line approach. 30th ACM/SIGAPP Symposium on Applied Computing (SAC 2015), volume 1, pp 261-263, Salamanca, Spain.

Mellouli, S., Bouslama, F., \& Akande, A. (2010). An ontology for representing financial headline news. Journal of Web Semantics, 8(2-3), 203-208. http:// dx.doi.org/10.1016/j.websem.2010.02.001.

Murray, M. C., \& Pérez, J. (2015). Informing and performing: A study comparing adaptive learning to traditional learning. Informing Science: The International Journal of an Emerging Transdiscipline, 18, 111-125. Retrieved from http://www. inform.nu/Articles/Vol18/ISJv18p111-125Murray1572.pdf.

Myers, I. B., McCaulley, M. H., Quenk, N. L., \& Hammer, A. L. (1998). MBTI manual: A guide to the development and use of the Myers-Briggs type indicator (3rd ed.). Palo Alto, CA: Consulting Psychologists.

Ocepek, U., Bosnić, Z., Nančovska Šerbec, I., \& Rugelj, J. (2013). Exploring the relation between learning style models and preferred multimedia types. Computers and Education, 69, 343-355. http://dx.doi.org/10.1016/j.compedu.2013.07.029.

Ouf, S., Abd Ellatif, M., Salama, S. E., \& Helmy, Y. (2016). A proposed paradigm for smart learning environment based on semantic web. Computers in Human Behavior. http://dx.doi.org/10.1016/j.chb.2016.08.030 (in press)

Özyurt, Ö., \& Özyurt, H. (2015). Learning style based individualized adaptive elearning environments: Content analysis of the articles published from 2005 to 2014. Computers in Human Behavior, 52, 349-358. http://dx.doi.org/10.1016/ j.chb.2015.06.020.

Ramayah, M., Sivanandan, L., Nasrijal, N. H., Letchumanan, T., \& Leong, L. C. (2009). Preferred learning style: Gender influence on preferred learning style among 
business students. Journal of US-China Public Administration, 6(4), 65-78.

Rani, M., Nayak, R., \& Vyas, O. P. (2015). An ontology-based adaptive personalized elearning system, assisted by software agents on cloud storage. Knowledge-based Systems, 90, 33-48. http://dx.doi.org/10.1016/j.knosys.2015.10.002.

Riad, A., El-Minir, H., \& El-Ghareeb, H. (2009). Review of e-Learning Systems Convergence from Traditional Systems to Services based Adaptive and Intelligent Systems. In JCIT (pp. 108-131).

Riding, R. J. (1991). Cognitive styles analysis. Birmingham: Learning and Training Technology.

Sadler-Smith, E., \& Riding, R. (1999). Cognitive style and instructional preferences. Instructional Science, 27(5), 355-371. http://dx.doi.org/10.1023/A: 1003277503330.

Santos, O. C., \& Boticario, J. G. (2015). Practical guidelines for designing and evaluating educationally oriented recommendations. Computers and Education, 81, 354-374. http://dx.doi.org/10.1016/j.compedu.2014.10.008.

Staab, S., \& Studer, R. (2009). Handbook on ontologies. Decision Support Systems,
654. http://dx.doi.org/10.1007/978-3-540-92673-3.

Sure, Y. Staab, S., \& Studer, R. (2009). Ontology engineering methodology. In S. Staab, \& D. Rudi Studer (Eds.), Handbook on ontologies (pp. 135-152, international handbooks on information systems). Springer Berlin Heidelberg.

Thalmann, S. (2014). Adaptation criteria for the personalised delivery of learning materials: A multi-stage empirical investigation. Australasian Journal of Educational Technology, 30(1), 45-60. http://dx.doi.org/10.14742/ajet.v30i1.235.

Truong, H. M. (2016). Integrating learning styles and adaptive e-learning system: Current developments, problems and opportunities. Computers in Human Behavior, 55, 1185-1193. http://dx.doi.org/10.1016/j.chb.2015.02.014.

Witkin, H. A., Moore, C. A., Goodenough, D. R., \& Cox, P. W. (1977). Field-dependent and field- independent cognitive styles and their educational implications. Review of Educational Research, 47, 1-64.

Yasir, M., \& Sharif, S. (2011). An approach to adaptive e-learning hypermedia system based on learning styles ( AEHS-LS ): Implementation and evaluation. International Journal of Library and Information, 3, 15-28. 